\title{
Article \\ Characterizing HIV-1 Genetic Subtypes and Drug Resistance Mutations among Children, Adolescents and Pregnant Women in Sierra Leone
}

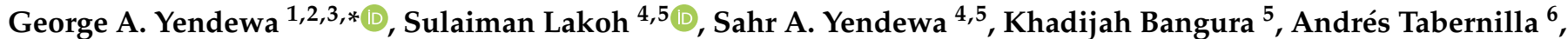 \\ Lucia Patiño ${ }^{6}$, Darlinda F. Jiba ${ }^{5}$, Alren O. Vandy ${ }^{5}$ D , Samuel P. Massaquoi ${ }^{5}$, Nuno S. Osório ${ }^{7}$ (D), \\ Gibrilla F. Deen ${ }^{4,5}$, Foday Sahr ${ }^{4}$, Robert A. Salata ${ }^{1,2}$ and Eva Poveda ${ }^{6}$ (D)
}

1 Department of Medicine, Case Western Reserve University School of Medicine, Cleveland, OH 44106, USA; ras@uhhospitals.org

2 Division of Infectious Diseases and HIV Medicine, University Hospitals Cleveland Medical Center, Cleveland, OH 44106, USA

3 Johns Hopkins Bloomberg School of Public Health, Baltimore, MD 21205, USA

4 Department of Medicine, College of Medicine and Allied Health Sciences, University of Sierra Leone, Freetown, Sierra Leone; lakoh2009@gmail.com (S.L.); syendewa@gmail.com (S.A.Y.); gibrilladeen1960@yahoo.com (G.F.D.); fsahr65@gmail.com (F.S.)

5 Ministry of Health and Sanitation, University of Sierra Leone Teaching Hospitals Complex, Freetown, Sierra Leone; khadijahbangura83@gmail.com (K.B.); darlindajiba.dj@gmail.com (D.F.J.); alrenvandy@gmail.com (A.O.V.); drspem@gmail.com (S.P.M.)

check for

updates

Citation: Yendewa, G.A.; Lakoh, S.; Yendewa, S.A.; Bangura, K.; Tabernilla, A.; Patiño, L.; Jiba, D.F.; Vandy, A.O.; Massaquoi, S.P.; Osório, N.S.; et al. Characterizing HIV-1 Genetic Subtypes and Drug Resistance Mutations among Children, Adolescents and Pregnant Women in Sierra Leone. Genes 2021, 12, 1314. https://doi.org/10.3390/ genes12091314

Academic Editor: Victor Asensi

Received: 23 June 2021

Accepted: 24 August 2021

Published: 26 August 2021

Publisher's Note: MDPI stays neutral with regard to jurisdictional claims in published maps and institutional affiliations.

Copyright: (C) 2021 by the authors. Licensee MDPI, Basel, Switzerland. This article is an open access article distributed under the terms and conditions of the Creative Commons Attribution (CC BY) license (https:/ / creativecommons.org/licenses/by/ $4.0 /)$.
6 Group of Virology and Pathogenesis, Galicia Sur Health Research Institute (IIS Galicia Sur), Complexo Hospitalario Universitario de Vigo, SERGAS-UVigo, 36213 Vigo, Spain; andrestabernilla@hotmail.com (A.T.); luciapatinoalvarez@gmail.com (L.P.); eva.poveda.lopez@sergas.es (E.P.)

7 Life and Health Sciences Research Institute (ICVS), School of Medicine, University of Minho, 4710-057 Braga, Portugal; nosorio@med.uminho.pt

* Correspondence: gay7@case.edu; Tel.: +1-(216)-844-2298

Abstract: Human immunodeficiency virus (HIV) drug resistance (HIVDR) is widespread in subSaharan Africa. Children and pregnant women are particularly vulnerable, and laboratory testing capacity remains limited. We, therefore, used a cross-sectional design and convenience sampling to characterize HIV subtypes and resistance-associated mutations (RAMs) in these groups in Sierra Leone. In total, 96 children (age 2-9 years, 100\% ART-experienced), 47 adolescents (age 10-18 years, $100 \%$ ART-experienced), and 54 pregnant women (>18 years, $72 \%$ ART-experienced) were enrolled. Median treatment durations were 36,84 , and 3 months, respectively, while the sequencing success rates were $45 \%, 70 \%$, and $59 \%$, respectively, among children, adolescents, and pregnant women. Overall, the predominant HIV-1 subtype was CRF02_AG (87.9\%, 95/108), with minority variants constituting $12 \%$. Among children and adolescents, the most common RAMs were M184V (76.6\%, $n=49 / 64), \mathrm{K} 103 \mathrm{~N}(45.3 \%, n=29 / 64), \mathrm{Y} 181 \mathrm{C} / \mathrm{V} / \mathrm{I}(28.1 \%, n=18 / 64), \mathrm{T} 215 \mathrm{~F} / \mathrm{Y}(25.0 \%, n=16 / 64)$, and V108I $(18.8 \%, n=12 / 64)$. Among pregnant women, the most frequent RAMs were K103N $(20.6 \%, n=7 / 34), \mathrm{M} 184 \mathrm{~V}(11.8 \%, n=4 / 34), \mathrm{Y} 181 \mathrm{C} / \mathrm{V} / \mathrm{I}(5.9 \%, n=2 / 34), \mathrm{P} 225 \mathrm{H}(8.8 \%, n=3 / 34)$, and $\mathrm{K} 219 \mathrm{~N} / \mathrm{E} / \mathrm{Q} / \mathrm{R}(5.9 \%, n=2 / 34)$. Protease and integrase inhibitor-RAMs were relatively few or absent. Based on the genotype susceptibility score distributions, $73 \%, 88 \%$, and $14 \%$ of children, adolescents, and pregnant women, respectively, were not susceptible to all three drug components of the WHO preferred first-line regimens per 2018 guidelines. These findings suggest that routine HIVDR surveillance and access to better ART choices may improve treatment outcomes in Sierra Leone.

Keywords: HIV; drug resistance; children; adolescents; pregnant women; resource-limited settings; Sierra Leone

\section{Introduction}

According to the World Health Organization (WHO) 2019 report on HIV drug resistance (HIVDR), the emergence and spread of HIVDR in low- and middle-income countries 
(LMICs) was a major factor limiting the success of antiretroviral treatment (ART) programs in achieving the 90-90-90 global targets for 2020 [1]. The situation was most dire in subSaharan Africa (SSA), which recorded the highest rates of HIVDR [1]. The WHO report further revealed that children and women are particularly vulnerable, with the prevalence of pre-treatment HIVDR to non-nucleos(t)ide reverse transcriptase inhibitors (NNRTIs) greater than $50 \%$ in children aged $<18$ months, while overall, women were twice as likely as men to harbor HIVDR mutations [1]. In response to the increasing rates of HIVDR globally, a five-year Global Action Plan on HIVDR (2017-2021) was rolled out, which called for the integration of HIVDR monitoring into broader HIV prevention and control efforts [2]. However, with recent disruptions in HIV care resulting from the COVID-19 pandemic, the overall impact of this global agenda remains uncertain.

Sierra Leone is a low-income West African country of 7.4 million people. The HIV epidemic in the country is described as generalized, with an estimated national HIV prevalence of $1.5 \%$ in 2018 , i.e., 70,000 people living with HIV, of whom 6600 were children aged 0-14 years [3]. The National AIDS response of Sierra Leone was first launched in 2002shortly after the country emerged from an 11-year period of civil warfare (1991-2002) - to help combat the growing HIV epidemic. Following the Ebola epidemic of 2014-2016, which led to severe disruptions in HIV service delivery in the country [4-7], the Government of Sierra Leone announced a five-year National Strategic Plan (NSP) on HIV / AIDS, which aimed to increase routine HIV testing activities, bolster the prevention of mother-to-child transmission (PMTCT) services, and expand ART coverage [8]. The UNAIDS 2019 report revealed that from 2010 to 2018, there was a 27\% decrease in AIDS-related deaths and a $22 \%$ decline in new HIV infections in the country [3].

Despite the welcome improvements in the areas of HIV care outlined above, barriers persist in other areas of the national AIDS response in Sierra Leone. For example, the UNAIDS 2019 report cited earlier observed that there was uneven progress across the 90-90-90 targets. In 2018, fewer than half (49\%) of PLWH in Sierra Leone knew their HIV status, and $41 \%$ of HIV-diagnosed patients were receiving ART, while only $26 \%$ of those on treatment were virally suppressed, the latter being likely due to a combination of poor treatment adherence and high prevalence of HIVDR in this setting [3]. In addition, recent studies by our group have observed other challenges in the local HIV care continuum, including high rates of late-stage HIV presentation [9], AIDS-associated in-hospital mortality [10], and high prevalence of HIV/HBV [11,12]. This is further compounded by the fact that as Sierra Leone and other LMICs have moved towards implementing integrase strand transfer inhibitor (INSTI)-based regimens as first-line ART, there is a dearth of country-specific studies to inform HIVDR prevention and management strategies due to limited laboratory testing capability.

In the first study characterizing HIVDR in Sierra Leone, we previously observed a pre-treatment HIVDR (PDR) prevalence of $37 \%(n=64)$ and an acquired HIVDR (ADR) prevalence $>95 \%(n=151)$ among adult HIV-infected individuals aged $>18$ years who were receiving routine HIV care at Connaught Hospital, the country's main referral health facility in Freetown [13]. Herein, we describe for the first time the prevalence of HIV-1 subtypes and resistance-associated mutations (RAMs) among children, adolescents, and pregnant women in Sierra Leone-three high-risk demographic groups that are disproportionately impacted by the HIV epidemic.

\section{Materials and Methods}

\subsection{Study Design, Populations, and Context}

We conducted a cross-sectional study of 3 demographic groups of HIV-infected patients selected consecutively during February through May 2019, as follows: (1) children aged 2-9 years inclusive, (2) adolescents aged 10-18 years inclusive, and (3) pregnant women aged $>18$ years. The children and adolescents were enrolled at the HIV Clinic at Ola during Children's Hospital, while the pregnant women were recruited at the HIV and Antenatal Clinic at the Princess Christian Maternity Hospital located in Freetown, 
Sierra Leone. Both hospitals serve as the national referral health centers for obstetric and pediatric cases and are major teaching affiliates of the College of Medicine and Allied Health Sciences of the University of Sierra Leone. The children and pregnant women were not biologically related.

Due to lack of HIVDR testing capability in Sierra Leone, none of the study participants had ever had baseline HIVDR testing at ART initiation; study participants were, therefore, selected consecutively using convenience sampling. At the time of study enrollment, the Sierra Leone National HIV Treatment Guidelines from 2017 (unpublished document from the National AIDS Control Programme of Sierra Leone) recommended a dual nucleos(t)ide reverse transcriptase inhibitor (NRTI) backbone, i.e., tenofovir/lamivudine (TDF/3TC), abacavir/lamivudine (ABC/3TC), or zidovudine/lamivudine (AZT/3TC) for plus the non-nucleotide reverse transcriptase inhibitors (NNRTIs) efavirenz (EFV) or nevirapine (NVP) as the preferred first-line regimen for all age groups. The ritonavir-boosted protease inhibitors (PIs) lopinavir (LPV/r) or atazanavir (ATV/r) were recommended as preferred second-line treatment for adults, or as alternative first-line for children $<3$ years who were exposed to nevirapine for prevention of MTCT.

\subsection{Ethical Considerations}

The study was conducted according to the guidelines of the Declaration of Helsinki and was approved by the Institutional Review Board of Case Western Reserve University/University Hospitals Cleveland Medical Center (approved 16 July 2019) and the Sierra Leone Ethics Scientific and Research Committee (approved 28 February 2019). Written informed consent was obtained from participants aged $\geq 15$ years, whereas parental or guardian consent was obtained for participants $<15$ years.

\subsection{Biosample Collection and Molecular Analysis}

For each patient, 3 to $5 \mathrm{~mL}$ of venous blood were collected into tubes (BD Vacutainer ${ }^{\circledR}$ K2 EDTA, Waltham, MA, USA) and centrifuged at $2000 \mathrm{~g}$ for $10 \mathrm{~min}$. Plasma was collected into cryogenic vials (Nunc ${ }^{\circledR}$ CryoTubes ${ }^{\circledR}$, Waltham, MA, USA) and stored at $-20{ }^{\circ} \mathrm{C}$ in Sierra Leone before transporting on dry ice $\left(-80^{\circ} \mathrm{C}\right)$ to the Galicia Sur Health Research Institute in Vigo, Spain, for molecular analysis. HIV reverse transcriptase (RT), protease (PR), and integrase (IN) were amplified from virus-derived plasma using an in-house Sanger sequencing protocol as previously described [13]. FASTA sequences were assembled using the Sequencer v5.4.6 DNA sequences analysis software (Gene Codes Corporation, Ann Arbor, MA, USA) and aligned with the reference sequence HXB2 (GenBank accession number K03455.1). HIV genetic subtypes and HIVDR mutations were identified and interpreted using the Stanford HIVDR database (freely available online at http:/ / hivdb. stanford.edu, accessed on 21 June 2020).

The genotypic susceptibility score (GSS), which estimates the number of HIV active drugs in a given combination ART regimen, was calculated as follows: (1) susceptible and potential low-level resistance were scored as 1, (2) low-level and intermediate resistance were pooled as intermediate and scored as 0.5 , and high-level resistance was scored as 0 . The GSS was assigned by summing the individual resistance scores for each first-line drug in the combination ART regimen as we previously described [13].

\subsection{Statistical Analyses}

Statistical analysis was performed using the Statistical Package for the Social Sciences software (SPSS 26.0, Chicago, IL, USA). Categorical variables were presented as frequency (percentages) and were compared using Pearson's chi-squared test. Continuous variables were expressed as median (interquartile range, IQ; or range) and compared using the non-parametric Mann-Whitney U-test or Kruskal-Wallis test, where appropriate. $p<0.05$ was considered statistically significant. 


\section{Results}

\subsection{Characteristics of the Study Population}

A total of 197 PLWH were enrolled in the study, consisting of 96 children, 47 adolescents, and 54 pregnant women. Table 1 describes the main demographic and clinical characteristics of the three demographic groups. About half of children $51.0 \%, 49 / 96$ ) and adolescents $(53.2 \%, 25 / 47)$ were male, with median ages 5 years (IQR $4-7)$ and 13 years (IQR 10-15), respectively. The median CD4 counts were 985 (IQR 596-1407) cells $/ \mathrm{mm}^{3}$ and 544 (IQR $260-849$ ) cells $/ \mathrm{mm}^{3}$, respectively, with $100 \%$ of children and $93.6 \%$ of adolescents having acquired HIV through MTCT. All children and adolescents $(100 \%)$ were ART-experienced, with a median treatment duration of 36 (IQR 12-60) months and 84 (IQR $60-108)$ months, respectively. The majority of children $(81.3 \%, 78 / 96)$ and adolescents $(53.2 \%, 25 / 47)$ were on first-line ART.

For the pregnant women, the median age were 26 years (IQR 23-31) and the median CD4 count was 526 cells / mm3 (IQR 459-698). The majority $(72.2 \%, 39 / 54)$ were ARTexperienced with median ART duration of 3 months (range 1-96) and were receiving tenofovir/lamivudine/efavirenz, TDF/3TC/EFV (72.2\%, 39/54). Over a quarter of the pregnant women $(27.8 \%, 15 / 54)$ were new HIV diagnosis, with the majority of them $(73.3 \%$, $11 / 15)$ diagnosed during the second or third trimester of pregnancy.

\subsection{HIV Sequence Distributions by Demographic Groups}

Plasma samples were analyzed from all 197 patients, and the HIV pol region was successfully sequenced in 108 patients, distributed as follows: 43 children, 33 adolescents, and 32 pregnant women. This yielded an overall sequencing success rate of $54.8 \%(108 / 197)$. The sequencing success rates by demographic groups were as follows: children, $44.8 \%$ (43/96); adolescents, 70.2\% (33/47); and pregnant women, 59.3\% (32/54).

\subsection{HIV Genotypic Subtypes}

The majority of patients were infected with the HIV-1 subtype CRF02_AG $(87.9 \%$, $95 / 108)$, followed by subtypes $G(9.2 \%, 10 / 108), A(1.8 \%, 2 / 108)$, and C $(0.9 \%, 1 / 108)$.

\subsection{Prevalence of RAMS among Children and Adolescents}

Genotypic resistance testing was performed on all 96 children (100\%) and 47 adolescents $(100 \%)$, which yielded 64 RT, 57 PR, and 67 IN sequences.

\subsubsection{NRTIs and NNRTIs}

Nearly $80 \%$ (51/64) of RT sequences from children and adolescents harbored RAMs to NRTIs and NNRTIs.

A total of 117 NRTI RAMs were identified from these two groups and were distributed as follows: as single RAMs $(32.8 \%, n=21 / 64)$, or in combinations of two $(20.3 \%, n=13 / 64)$, three $(12.5 \%, n=8 / 64)$, or five RAMs $(9.4 \%, n=6 / 64)$. On the other hand, 133 NNRTI RAMs were identified, either as a single RAM $(18.8 \%, n=12 / 64)$, or in combinations of two $(18.8 \%, n=12 / 64)$, or three $(26.6 \%, n=17 / 64)$ RAMs.

The most prevalent RT RAMs among children and adolescents and their relative proportions were as follows: $\mathrm{M} 184 \mathrm{~V}(76.6 \%, n=49 / 64), \mathrm{K} 103 \mathrm{~N}(45.3 \%, n=29 / 64), \mathrm{Y} 181 \mathrm{C} / \mathrm{V} / \mathrm{I}$ $(28.1 \%, n=18 / 64), \mathrm{T} 215 \mathrm{~F} / \mathrm{Y}(25.0 \%, n=16 / 64), \mathrm{V} 108 \mathrm{I}(18.8 \%, n=12 / 64), \mathrm{A} 98 \mathrm{G}(15.6 \%$, $n=10 / 64)$, G190A $(12.5 \%, n=8), \mathrm{K} 101 \mathrm{E} / \mathrm{H}(12.5 \%, n=8), \mathrm{M} 41 \mathrm{~L}(10.9 \%, n=7 / 64), \mathrm{L} 74 \mathrm{I} / \mathrm{V}$ $(10.9 \%, n=7 / 64)$, and H221Y $(10.9 \%, n=7 / 64)$ (Figure 1a,b). 
Table 1. Baseline characteristics of the study population.

\begin{tabular}{|c|c|c|c|}
\hline Characteristics & $\begin{array}{l}\text { Children } \\
\mathrm{N}=96\end{array}$ & $\begin{array}{l}\text { Adolescents } \\
\quad \mathrm{N}=47\end{array}$ & $\begin{array}{l}\text { Pregnant Women } \\
\quad \mathrm{N}=54\end{array}$ \\
\hline \multicolumn{4}{|l|}{ Gender } \\
\hline Male & $49(51.0)$ & $25(53.2)$ & - \\
\hline Female & $47(49.0)$ & $22(46.8)$ & $54(100)$ \\
\hline \multicolumn{4}{|l|}{ Age, years } \\
\hline Median (IQR) & $5(4-7)$ & $13(10-15)$ & $26(23-31)$ \\
\hline $2-5$ & $50(52.1)$ & - & - \\
\hline $6-9$ & $46(47.9)$ & - & - \\
\hline $10-18$ & - & $47(100)$ & - \\
\hline $18-30$ & - & - & $36(75.0)$ \\
\hline $31-40$ & - & - & $12(25.0)$ \\
\hline \multicolumn{4}{|l|}{ Mode of HIV acquisition } \\
\hline Mother to child transmission & $96(100)$ & $44(93.6)$ & - \\
\hline Sexually transmitted & - & $3(6.4)$ & - \\
\hline $\begin{array}{c}\text { Median duration of pregnancy (IQR), } \\
\text { weeks }\end{array}$ & - & - & $22(16-29)$ \\
\hline \multicolumn{4}{|l|}{$\begin{array}{l}\text { Trimester of newly diagnosed } \\
\mathrm{N}=15(100 \%)\end{array}$} \\
\hline First (1-13 weeks) & - & - & $4(26.7)$ \\
\hline Second (14-26 weeks) & - & - & $8(53.3)$ \\
\hline Third (27+ weeks) & - & - & $3(20.0)$ \\
\hline CD4 count, median (IQR), cells $/ \mathrm{mm}^{3}$ & $985(596-1407)$ & $544(260-849)$ & $526(459-698)$ \\
\hline \multicolumn{4}{|l|}{ Current ART regimens } \\
\hline $\mathrm{TDF}+3 \mathrm{TC}+\mathrm{EFV}$ & - & $7(14.9)$ & $39(72.2)$ \\
\hline $\mathrm{AZT}+3 \mathrm{TC}+\mathrm{EFV}$ & $7(7.3)$ & $4(8.5)$ & - \\
\hline $\mathrm{AZT}+3 \mathrm{TC}+\mathrm{NVP}$ & $25(26.0)$ & $20(42.6)$ & - \\
\hline $\mathrm{AZT}+3 \mathrm{TC}+\mathrm{LPV} / \mathrm{r}$ & $6(6.3)$ & - & - \\
\hline $\mathrm{ABC}+3 \mathrm{TC}+\mathrm{EFV}$ & $27(28.1)$ & $9(19.1)$ & - \\
\hline $\mathrm{ABC}+3 \mathrm{TC}+\mathrm{NVP}$ & $15(15.6)$ & $2(4.3)$ & - \\
\hline $\mathrm{ABC}+3 \mathrm{TC}+\mathrm{LPV} / \mathrm{r}$ & $16(16.7)$ & $5(10.6)$ & - \\
\hline Not on ART & - & - & $15(27.8)$ \\
\hline \multicolumn{4}{|l|}{ Type of ART } \\
\hline First-line * & $78(81.3)$ & $25(53.2)$ & $39(72.2)$ \\
\hline Second-line $* *$ & $18(18.8)$ & $22(46.8)$ & - \\
\hline \multicolumn{4}{|l|}{ Duration of ART exposure, months } \\
\hline Median (IQR) & $36(12-60)$ & $84(60-108)$ & $3(1-9)$ \\
\hline$\leq 24$ & $42(43.8)$ & $8(17.0)$ & $39(72.2)$ \\
\hline $25-48$ & $23(24.0)$ & $2(4.3)$ & - \\
\hline $49-60$ & $23(24.0)$ & $12(25.5)$ & - \\
\hline$>60$ & $6(8.4)$ & 25 53.2) & - \\
\hline
\end{tabular}

Abbreviations: ART, antiretroviral therapy; IQR, interquartile range. ${ }^{*}$ First-line and ${ }^{* *}$ Second-line regimens based on the 2017 Sierra Leone HIV treatment guidelines (unpublished document from the National AIDS Control Programme of Sierra Leone); -, not applicable; bold distinguishes between variables with sub-categories

\subsubsection{PIs and INSTIs}

We observed 4 PI-associated RAMs in 6 children/adolescents, as follows: the combination mutation I54V + V82A $(n=2), \mathrm{M} 46 \mathrm{I} / \mathrm{M}(n=1)$, and I84I/V $(n=1)$. The combination mutation $154 \mathrm{~V}+\mathrm{V} 82 \mathrm{~A}$ confers intermediate resistance to all the currently approved PIs 
with the exception of darunavir, which retains full activity. Interestingly, there was no documented record of prior exposure to PI-based ART in these 6 patients.
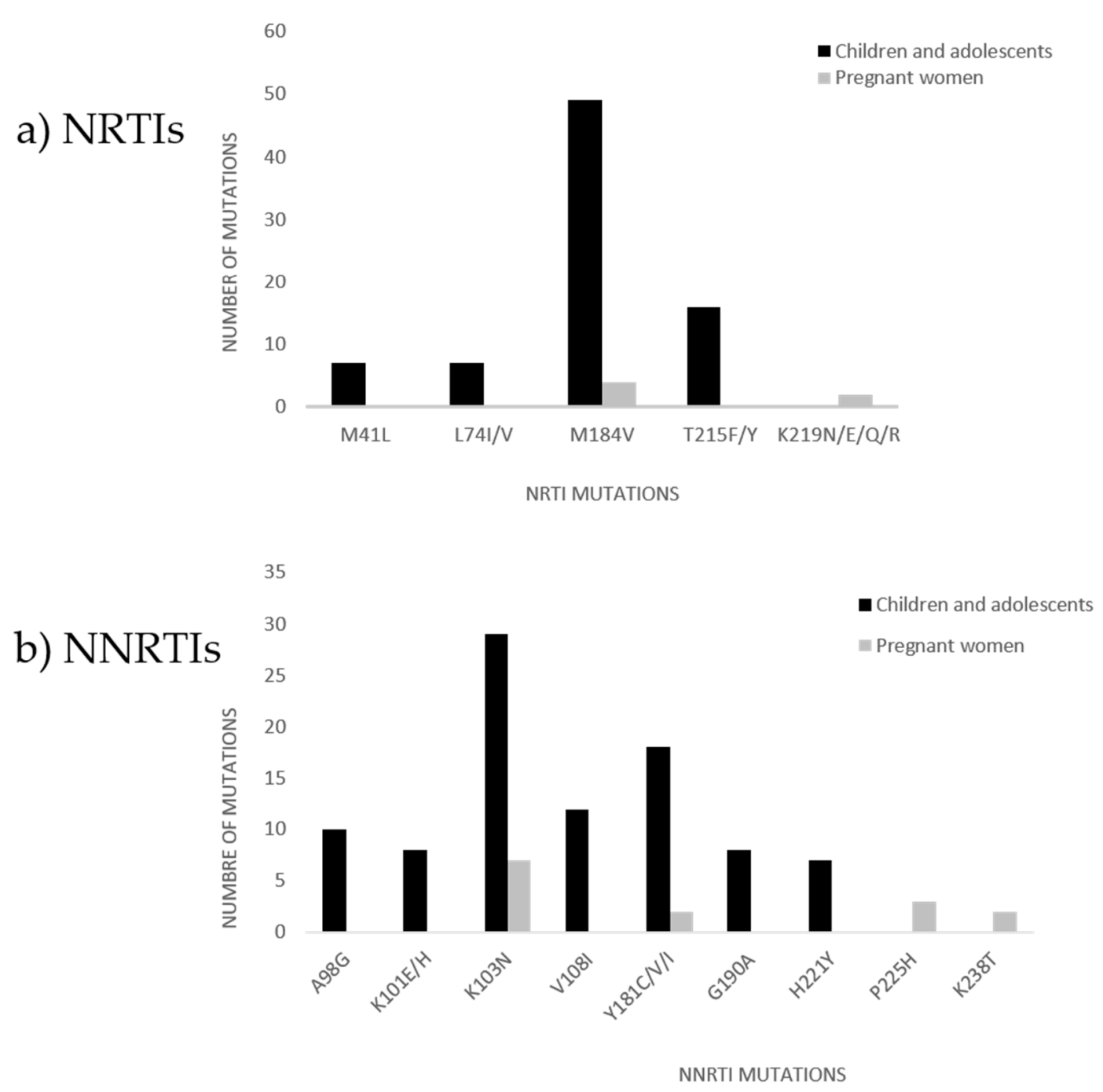

Figure 1. Common mutations to (a) NRTIs and (b) NNRTIs in children, adolescents, and pregnant women. Abbreviations: NRTI, nucleos(t)ide reverse transcriptase inhibitor; NNRTI, non-nucleotide reverse transcriptase inhibitor.

Polymorphic accessory INSTI-selected mutations, which have minimal effect on INSTI susceptibility were observed in 8 children/adolescents, as follows: T97A $(n=2)$, E157Q $(n=5)$, and S230SR $(n=1)$.

\subsubsection{Genotypic Susceptibility Scores}

Based on the GSS estimates, $76.3 \%$ had GSS $<3$ to the WHO preferred first-line DTG-based ART, whereas $66.6 \%$ to $70 \%$ of the children had a GSS $<3$ to the WHO preferred/alternative second-line PI-based regimens, respectively, i.e., they harbored genotypes that were not fully susceptible to all three antiretroviral drugs in the regimen (Table 2). Similarly, $87.5 \%$ and $92.8 \%$ to $100 \%$ of adolescents harbored genotypes that were not susceptible to the WHO preferred first-line and second-line regimens, respectively (Table 2). 
Table 2. Genotypic scores to the preferred first-line and second-line ART based on the 2018 WHO guidelines.

\begin{tabular}{|c|c|c|c|c|}
\hline Population & $\begin{array}{c}\text { Preferred } \\
\text { WHO First-Line Regimens }\end{array}$ & $\begin{array}{c}\text { GSS }<3 \\
n(\%)\end{array}$ & $\begin{array}{l}\text { Preferred or Alternative } \\
\text { WHO Second-Line Regimens }\end{array}$ & $\begin{array}{c}\text { GSS }<3 \\
n(\%)\end{array}$ \\
\hline \multirow{5}{*}{ Children } & $\mathrm{AZT}+3 \mathrm{TC}+\mathrm{DTG}$ & $29(76.3)$ & $\mathrm{AZT}+3 \mathrm{TC}+\mathrm{LPV} / \mathrm{r}($ or ATV $/ \mathrm{r})$ & $24(68.6)$ \\
\hline & $\mathrm{ABC}+3 \mathrm{TC}+\mathrm{DTG}$ & $29(76.3)$ & $\mathrm{AZT}+3 \mathrm{TC}+\mathrm{DRV} / \mathrm{r}$ & $24(68.6)$ \\
\hline & & & $\mathrm{ABC}+3 \mathrm{TC}+\mathrm{LPV} / \mathrm{r}($ or ATV $/ \mathrm{r})$ & $24(68.6)$ \\
\hline & & & $\mathrm{ABC}+3 \mathrm{TC}+\mathrm{DRV} / \mathrm{r}$ & $6(66.6)$ \\
\hline & & & $\mathrm{ABC}+3 \mathrm{TC}+\mathrm{RAL}$ & $7(70.0)$ \\
\hline \multirow{4}{*}{ Adolescents } & $\mathrm{AZT}+3 \mathrm{TC}+\mathrm{DTG}$ & $14(87.5)$ & $\mathrm{AZT}+3 \mathrm{TC}+\mathrm{LPV} / \mathrm{r}($ or ATZ/r) & $13(92.8)$ \\
\hline & $\mathrm{ABC}+3 \mathrm{TC}+\mathrm{DTG}$ & $14(87.5)$ & $\mathrm{AZT}+3 \mathrm{TC}+\mathrm{DRV} / \mathrm{r}$ & $13(92.8)$ \\
\hline & $\mathrm{TDF}+3 \mathrm{TC}+\mathrm{DTG}$ & $14(87.5)$ & $\mathrm{ABC}+3 \mathrm{TC}+\mathrm{LPV} / \mathrm{r}($ or $\mathrm{ATZ} / \mathrm{r})$ & $24(68.6)$ \\
\hline & & & $\mathrm{ABC}+3 \mathrm{TC}+\mathrm{DRV} / \mathrm{r}$ & $6(100)$ \\
\hline \multirow{6}{*}{$\begin{array}{l}\text { Pregnant } \\
\text { women }\end{array}$} & $\mathrm{TDF}+3 \mathrm{TC}($ or FTC) + DTG & $3(13.6)$ & $\mathrm{TDF}+3 \mathrm{TC}($ or FTC) $+\mathrm{ATV} / \mathrm{r}$ & $3(17.6)$ \\
\hline & $\mathrm{ABC}+3 \mathrm{TC}+\mathrm{DTG}$ & $3(13.6)$ & $\mathrm{TDF}+3 \mathrm{TC}($ or FTC) + LPV $/ \mathrm{r}$ & $3(17.6)$ \\
\hline & $\mathrm{AZT}+3 \mathrm{TC}+\mathrm{DTG}$ & $3(13.6)$ & $\mathrm{TDF}+3 \mathrm{TC}($ or FTC) + DRV $/ \mathrm{r}$ & $3(17.6)$ \\
\hline & & & $\mathrm{AZT}+3 \mathrm{TC}+\mathrm{ATV} / \mathrm{r}$ & $3(17.6)$ \\
\hline & & & $\mathrm{AZT}+3 \mathrm{TC}+\mathrm{LPV} / \mathrm{r}$ & $3(17.6)$ \\
\hline & & & $\mathrm{AZT}+3 \mathrm{TC}+\mathrm{DRV} / \mathrm{r}$ & $3(17.6)$ \\
\hline
\end{tabular}

Abbreviations: ART, antiretroviral therapy; GSS, genotypic susceptibility scores.

\subsection{Prevalence of RAMS among Pregnant Women}

Genotypic resistance testing was performed on all 54 pregnant women (100\%). A total of 34 RT, 27 PR, and 33 IN sequences were obtained, which were distributed as follows based on treatment status: (1) $27 \mathrm{RT}, 21 \mathrm{PR}$, and $24 \mathrm{IN}$ from ART-experienced patients $(n=39)$; and (2) 7 RT, 6 PR, and 9 IN from the newly diagnosed ART-naïve patients $(n=15)$.

\subsubsection{NRTIs and NNRTIs}

Overall, $76.5 \%$ ( $n=26 / 34)$ of RT sequences harbored RAMs to NRTIs or NNRIs in pregnant women, which were distributed as follows: (1) ART-experienced (59.3\%, $n=16 / 27)$, and (2) newly diagnosed ART-naïve (71.4\%, $n=5 / 7)$.

A total of 9 NRTI RAMs were identified, as follows: (1) 7 RAMs in the ART-experienced group, which occurred as a single mutation $(2.6 \%, n=1 / 39)$ or as a combination of two mutations $(7.7 \%, n=3 / 39)$; and (2) 2 RAMs in the newly diagnosed ART-naïve, which occurred as a combination of two mutations $(28.6 \%, n=2 / 7)$. On the other hand, 18 NNRTI RAMs were identified, as follows: (1) 5 RAMs in the newly diagnosed ART-naïve patients, which occurred as a combination of two $(14.3 \%, n=1 / 7)$ or three mutations $(14.3 \%, n=1 / 7)$; and (2) 13 RAMs in the ART-experienced patients, which occurred as a single mutation $(7.4 \%, n=2 / 27)$ or in combinations of two $(7.4 \%, n=2 / 27)$, three $(3.7 \%, n=1 / 20)$ or four mutations $(3.7 \%, n=1 / 27)$.

The most prevalent RT RAMs in pregnant women were as follows: $\mathrm{K} 103 \mathrm{~N}(20.6 \%$, $n=7 / 34), \mathrm{M} 184 \mathrm{~V}(11.8 \%, n=4 / 34), \mathrm{Y} 181 \mathrm{C} / \mathrm{V} / \mathrm{I}(5.9 \%, n=2 / 34), \mathrm{P} 225 \mathrm{H}(8.8 \%, n=3 / 34)$, $\mathrm{K} 219 \mathrm{~N} / \mathrm{E} / \mathrm{Q} / \mathrm{R}(5.9 \%, n=2 / 34)$, and K238T $(5.9 \%, n=2 / 34)$ (Figure 1a,b).

\subsubsection{PIs and INSTIs}

No PIs RAMs were observed, whereas three accessory INSTI-selected mutations T97A $(n=1)$, E157Q $(n=2)$, and G163R $(n=1)$, which have minimal effect on INSTI susceptibility, were observed in four pregnant women. 


\subsubsection{Genotypic Susceptibility Scores}

Based on GSS distributions, $13.6 \%$ of the pregnant women had GSS $<3$ to the WHO preferred first-line DTG-based ART, whereas $66.6 \%$ to $100 \%$ of the pregnant women had a GSS $<3$ to the WHO preferred/alternative second-line PI-based regimens, respectively, i.e., they harbored genotypes that were not fully susceptible to all three antiretroviral drugs in the regimen (Table 2).

\section{Discussion}

This is the first study from Sierra Leone to characterize HIV-1 genetic subtypes and HIVDR among children, adolescents, and pregnant women. In this cross-sectional survey, we assessed the prevalence of RAMs in a cohort of 96 children aged 2-9 years, 47 adolescents aged 10-18 years, and 54 pregnant women $>18$ years at the two main referral children's and women's health facilities, respectively, in Freetown. We observed a high prevalence of RAMs to NRTIs (up to 77\% in children and adolescents) and NNRTIs (nearly 50\%) in the three demographic groups, whereas the prevalence of RAMs to PIs and INSTIs was relatively low or absent. Our findings confirm the situation previously described in the WHO 2019 HIVDR report [1], as well as other recent studies from the West Africa region, including our previous study describing HIVDR among adult PLWH in Sierra Leone [13-18].

Current international ART treatment guidelines recommend a dual NRTI-backbone in combination with an INSTI or a boosted-PI with a high genetic barrier to developing resistance such as darunavir/ritonavir (DRV/r) in the treatment of HIV-infected individuals [12,19-21]. Sierra Leone is an INSTI-naïve stetting, as INSTI-based ART was only recently introduced in 2021. Despite this, we found several polymorphic accessory INSTIselected mutations (e.g., T97A and E157Q) in eight children/adolescents and four pregnant women associated with low-level drug resistance. Reassuringly, however, we did not observe any clinically relevant INSTI RAMs in this study or in our previous HIVDR study from Sierra Leone. These findings corroborate current evidence, derived largely from studies in B subtypes, which suggests that globally, the prevalence of major INSTI RAMs to DTG is very low among PLWH without prior exposure to DTG [22-24], supporting the notion that DTG may be safe to use in this INSTI-naïve setting.

Despite its high potency, good tolerability, and high genetic barrier to developing drug resistance, safety concerns persist around the peri-conception use of DTG in women of child-bearing age and during the first trimester of pregnancy, due to the reported higher incidence of neural tube defects [25-27]. Another point of caution that has been raised in relation to the roll-out of DTG in SSA is that, due to insufficient studies on the subject, it is uncertain what impact, if any, circulating HIV non-B subtypes in SSA will have on the efficacy of DTG. Several studies have observed a higher frequency of INSTIassociated polymorphisms among non-B subtypes [28-31]. However, current experience with DTG and other INSTIs have shown high rates of virologic suppression $(>90 \%)$ in non-B subtypes, including CRF02_AG, the dominant HIV subtype circulating in Sierra Leone and in West and Central Africa [32-35]. Notwithstanding, this is likely to be an area of careful investigation in the future, as DTG becomes more widely used in this region, which has the most diverse genetic subtypes.

We found that M184V was the most frequent NRTI RAM, occurring with a prevalence of nearly $77 \%$ among children/adolescents and $11 \%$ of pregnant women. This mutation is selected by 3TC and emtricitabine (FTC), which significantly reduces their activity (by about 100- to 1000-fold, respectively) while conferring low-level resistance to ABC [36-38]. In contrast, M184V induces hypersusceptibility to TDF and AZT, while simultaneously limiting the emergence of drug resistance to both agents [39-41]. This is particularly relevant to the Sierra Leone context, given that the most commonly used NRTI in clinical care in Sierra Leone is 3TC, with $100 \%$ of our ART-experienced study participants having been exposed to it. In the adult study participants, TDF was the other commonly used NRTI, while in children and adolescents, either ABC or AZT constituted the second NTRI 
option. Taken all together, these findings may have two important clinical implications. Firstly, patients failing first-line ART based on the 2017 ART guidelines in Sierra Leone have limited options for second-line therapy, as estimated by the GSS (Table 2). Secondly, with high rates of $\mathrm{HIV} / \mathrm{HBV}$ coinfection in this setting (up to $22 \%$ based on previous studies by our group) [11,12] - a large proportion of patients on 3TC-based and/or TDF-sparing ART regimens are likely to be receiving suboptimal treatment for both HIV and HBV infections, heightening their risk for progression to AIDS, liver cirrhosis, and end-stage liver disease. Thus, screening for HBV in all HIV-infected patients before ART initiation and at the time of switching ART is essential to guiding optimal ART choice.

The marked disparity in frequency of M184V-selected viruses among children and adolescents (77\%) and pregnant women (11\%) was noteworthy. Studies have shown that $\mathrm{M} 184 \mathrm{~V}$ is associated with reduced replicative activity in the absence of drug pressure, compared with the wild-type (WT) virus [42-44]. The children and adolescents were all $(100 \%)$ ART-experienced for a much longer duration (median of 48 months) compared with the pregnant women (72.2\% ART-experienced for a median duration of 3 months) and would, therefore, be expected to accumulate more M184V viruses, due to the overall higher drug exposure. We hypothesize that this finding may also have been driven, in part, by differing levels of medication adherence in the three study groups. It is plausible that while adherence may have been low in both groups, it was comparatively much lower among pregnant women, resulting in less pharmacologic pressure in this group and increasing the reversion rate of M184V-selected viruses to WT viruses. We were unable to assess drug adherence to confirm this hypothesis. Poor ART adherence remains a widespread global challenge, and effective strategies to address this problem will help in limiting drug resistance, maximize the benefits of ART, and improve treatment outcomes.

The prevalence of the NNRTI mutation K103N, which is selected by EFV and NVP was high in all three study groups. This finding is in line with reports from the SSA, where the frequency of K103 has exceeded $10 \%$ in most LMICs reporting HIVDR surveillance data to the WHO [1]. In this study, the prevalence of K103 (was much lower (i.e., $45.3 \%$ in children/adolescents and $20.6 \%$ in pregnant women) than we previously described among the adult population receiving ART in Sierra Leone [13]. There are limited studies on MTCT rates in Sierra Leone; however, according to programmatic data from 2016, PMTCT ART coverage was $67.3 \%$ [45] and there was a decline in MTCT rates from $22 \%$ (2011) to $13 \%$ (2014) countrywide [8]. Despite this, nearly $75 \%$ of pregnant women who were newly diagnosed with HIV in this study were diagnosed in the second or third trimesters. If this observation is reflective of broader trends, the combination of the high prevalence of RAMs to NVP (the principal drug used in PMTCT treatment in Sierra Leone) and late diagnosis of HIV during pregnancy may have far-reaching policy implications for the success of PMTCT efforts in Sierra Leone and LMICs with similar MTCT characteristics.

Our study had several limitations. Firstly, our study enrolled a small sample size from a single clinical site, which limits the generalizability of study findings. Secondly, although the issues of pretreatment (PDR) and/or transmitted drug HIV drug resistance (TDR) remain important barriers to reducing vertical HIV transmission, we were unable to assess this fully due to the relatively small number of ART-naïve pregnant study population. Thirdly, due to insufficient plasma samples, VL measurement could not be performed for all patients. Finally, because the majority of the patients were on ART for a long period of time (median period 36 months and 84 months in children and adolescents, respectively), we suspect that a substantial proportion of these patients were either virologically suppressed or had low viremia, which may have contributed to the low rate of sequencing success, especially among children. Nonetheless, our findings contribute to our current understanding of circulating HIV strains and HIVDR among three vulnerable populations that are disproportionately affected by the growing HIV epidemic and may have some policy implications for PMTCT program activities. Larger studies are needed to assess the countrywide HIVDR prevalence rates and associated factors to help inform treatment strategies and public health approaches in the national AIDS response in Sierra Leone. 


\section{Conclusions}

We observed a high prevalence of circulating RAMs to NRTIs (especially 3TC) and NNRTIs (EFV and NVP) among HIV-infected children, adolescents, and pregnant women in Freetown, Sierra Leone. In contrast, the prevalence of RAMs to PIs and INSTI was low or absent. Although the three populations were not biologically related, our findings may have implications for the success of PMTCT efforts in the country. Furthermore, our findings suggest the need for a national HIVDR surveillance program to help guide ART choice and improve treatment outcomes for patients.

Author Contributions: Conceptualization, G.A.Y., S.L., R.A.S. and E.P.; methodology, G.A.Y. and E.P.; validation, G.A.Y., N.S.O. and E.P.; formal analysis, G.A.Y., N.S.O. and E.P.; investigation, G.A.Y., S.L., S.A.Y., K.B., A.T., L.P., D.F.J., A.O.V., S.P.M., G.F.D., F.S. and E.P.; resources, G.A.Y., S.L., R.A.S. and E.P.; data curation, G.A.Y. and E.P.; writing - original draft preparation, G.A.Y. and E.P.; writingreview and editing, all authors; supervision, G.A.Y. and E.P.; project administration, G.A.Y. and E.P.; funding acquisition, G.A.Y. and E.P. All authors have read and agreed to the published version of the manuscript.

Funding: This research was funded by the Roe Green Travel Medicine and Global Health Award 2019 (Award Number J0628), University Hospitals Cleveland Medical Center (G.A.Y.), Instituto de Salud Carlos III and Fondo Europeo de Desarrollo Regional-FEDER, Red Española de Investigación en SIDA (RD16/0025/0026) (E.P.), Xunta Galicia-Fondo Social Europeo (IN606A-2016/023) (E.P.) and Fundación Biomédica Galicia Sur (E.P.).

Institutional Review Board Statement: The study was conducted according to the guidelines of the Declaration of Helsinki and was approved by the Institutional Review Board of Case Western Reserve University/University Hospitals Cleveland Medical Center (approved 16 July 2019) and the Sierra Leone Ethics Scientific and Research Committee (approved 28 February 2019).

Informed Consent Statement: Written informed consent was obtained from participants aged $\geq 15$ years, whereas parental or guardian consent was obtained for participants $<15$ years.

Data Availability Statement: The raw de-identified data supporting the conclusions of this article will be made available by the authors, without undue reservation, to any qualified researcher.

Acknowledgments: We acknowledge the HIV infected women and children of Sierra Leone who made this work possible. We also acknowledge Mohamed Sam (laboratory technician) at 34 Military Hospital, the nursing staff at the Antenatal Care Clinic at the Princess Christian Maternity Hospital and the Ola during Children's Hospital in Freetown, for their dedication and passion for HIV Medicine.

Conflicts of Interest: The authors declare no conflict of interest.

\section{References}

1. WHO. HIV Drug Resistance Report 2019. 2019. Available online: https://www.who.int/hiv/pub/drugresistance/hivdr-report2019/en/ (accessed on 22 June 2021).

2. WHO. Global Action Plan on HIV Drug Resistance (2017-2021). 2017. Available online: https://apps.who.int/iris/bitstream/ handle/10665/255883/9789241512848-eng.pdf?sequence=1 (accessed on 22 June 2021).

3. UNAIDS. UNAIDS Data 2019. 2019. Available online: https://www.unaids.org/en/resources/documents/2019/2019-UNAIDSdata (accessed on 22 June 2021).

4. Yendewa, G.A.; Poveda, E.; Yendewa, S.A.; Sahr, F.; Quiñones-Mateu, M.E.; Salata, R.A. HIV / AIDS in Sierra Leone: Characterizing the Hidden Epidemic. AIDS Rev. 2018, 20, 104-113. [CrossRef] [PubMed]

5. Nagel, E.; Blackowicz, M.J.; Sahr, F.; Jarrett, O.D. Impact of the Ebola epidemic on clinical outcomes of HIV-infected soldiers and their dependents in Sierra Leone. Int. J. STD AIDS 2019, 30, 106-112. [CrossRef] [PubMed]

6. Gamanga, A.H.; Owiti, P.; Bhat, P.; Harries, A.D.; Kargbo-Labour, I.; Koroma, M. The Ebola outbreak: Effects on HIV reporting, testing and care in Bonthe district, rural Sierra Leone. Public Health Action 2017, 7, S10-S15. [CrossRef] [PubMed]

7. Parpia, A.S.; Ndeffo-Mbah, M.L.; Wenzel, N.S.; Galvani, A.P. Effects of Response to 2014-2015 Ebola Outbreak on Deaths from Malaria, HIV/AIDS, and Tuberculosis, West Africa. Emerg. Infect. Dis. 2016, 22, 433-441. [CrossRef]

8. National HIV/AIDS Secretariat 2016. National Strategic Plan 2016-2020. Available online: https://www.nas.gov.sl/images/ stories/publications/Sierra\%20Leone\%20National\%20Strategic\%20Plan\%202016\%20-\%202020.pdf (accessed on 22 June 2021).

9. Yendewa, G.A.; Poveda, E.; Lakoh, S.; Yendewa, S.A.; Jiba, D.F.; Salgado-Barreira, A.; Sahr, F.; Salata, R.A. High prevalence of late-stage disease in newly diagnosed HIV patients in Sierra Leone. Open Forum Infect. Dis. 2018, 5, ofy208. [CrossRef] [PubMed] 
10. Lakoh, S.; Jiba, D.F.; Kanu, J.E.; Poveda, E.; Salgado-Barreira, A.; Sahr, F.; Sesay, M.; Deen, G.F.; Sesay, T.; Gashau, W.; et al. Causes of hospitalization and predictors of HIV-associated in-hospital mortality in Sierra Leone: A Prospective Study. BMC Public Health 2019, 19, 1320. [CrossRef] [PubMed]

11. Yendewa, G.A.; Sahr, F.; Aguilera, A.; Lakoh, S.; Sesay, M.; Deen, G.F.; Patiño, L.; Poveda, E.; Salata, R.A. Seroprevalence of hepatitis B, hepatitis $C$ and human T-cell lymphotropic virus infections in human immunodeficiency virus-infected patients in Sierra Leone. Am. J. Trop. Med. Hyg. 2019, 100, 1521-1524. [CrossRef] [PubMed]

12. Yendewa, G.A.; Lakoh, S.; Yendewa, S.A.; Bangura, K.; Lawrence, H.; Patiño, L.; Jiba, D.F.; Vandy, A.O.; Murray, M.J.S.; Massaquoi, S.P.; et al. Prevalence of Hepatitis B Surface Antigen and Serological Markers of Other Endemic Infections in HIV-infected Children, Adolescents and Pregnant Women in Sierra Leone: A Cross-sectional Study. Int. J. Infect. Dis. 2020, 102, 45-52. [CrossRef]

13. Yendewa, G.A.; Sahr, F.; Lakoh, S.; Ruiz, M.; Patiño, L.; Tabernilla, A.; Deen, G.F.; Sesay, M.; Salata, R.A.; Poveda, E. Prevalence of Drug Resistance Mutations among ART-naïve and experienced HIV-infected patients in Sierra Leone. J. Antimicrob. Chemother. 2019, 74, 2024-2029. [CrossRef]

14. Villabona-Arenas, C.J.; Vidal, N.; Guichet, E.; Serrano, L.; Delaporte, E.; Gascuel, O.; Peeters, M. In-depth analysis of HIV-1 drug resistance mutations in HIV-infected individuals failing first-line regimens in West and Central Africa. AIDS 2016, 30, 2577-2589. [CrossRef]

15. Deletsu, S.D.; Maina, E.K.; Quaye, O.; Ampofo, W.K.; Awandare, G.A.; Bonney, E.Y. High resistance to reverse transcriptase inhibitors among persons infected with human immunodeficiency virus type 1 subtype circulating recombinant form 02_AG in Ghana and on antiretroviral therapy. Medicine 2020, 99, e18777. [CrossRef]

16. Mikasi, S.G.; Gichana, J.O.; Van der Walt, C.; Brado, D.; Obasa, A.E.; Njenda, D.; Messembe, M.; Lyonga, E.; Assoumou, O.; Cloete, R.; et al. HIV-1 Integrase Diversity and Resistance-Associated Mutations and Polymorphisms Among Integrase Strand Transfer Inhibitor-Naive HIV-1 Patients from Cameroon. AIDS Res. Hum. Retrovir. 2020. 36, 450-455. [CrossRef]

17. Chaplin, B.; Akanmu, A.S.; Inzaule, S.C.; Samuels, J.O.; Okonkwo, P.; Ilesanmi, O.; Adewole, I.F.A.; Asadu, C.; Khamofu, H.; Mpazanje, R.; et al. Association between HIV-1 subtype and drug resistance in Nigerian infants. J. Antimicrob. Chemother. 2019, 74, 172-176. [CrossRef]

18. Cissé, A.M.; Laborde-Balen, G.; Kébé-Fall, K.; Dramé, A.; Diop, H.; Diop, K.; FatouNiasse-Traoré; Coulibaly, M.; Have, N.N.; Vidal, N.; et al. High level of treatment failure and drug resistance to first-line antiretroviral therapies among HIV-infected children receiving decentralized care in Senegal. BMC Pediatr. 2019, 19, 47. [CrossRef]

19. Department of Health and Human Services. Adult and Adolescent Guidelines for the Use of Antiretroviral Agents in Adults and Adolescents with HIV. Available online: http:/ / aidsinfo.nih.gov/contentfiles/lvguidelines/AdultandAdolescentGL.pdf (accessed on 22 June 2021).

20. European AIDS Clinical Society. Guidelines Version 10.0. 2019. Available online: https://www.eacsociety.org/files/2019 _guidelines-10.0_final.pdf (accessed on 22 June 2021).

21. GESIDA. Documento de Consenso de Gesida/Plan Nacional sobre el SIDA Respecto al Tratamiento Antiretroviral en Adultos Infectados por el Virus de la Inmunodeficiencia Humana. Updated January 2018. 2018. Available online: http:/ / gesidaseimc. org/wcontent/uploads/2018/01/gesida_TAR_Gesida_y_PNS_2018.pdf (accessed on 22 June 2021).

22. Han, Y.S.; Mesplede, T.; Wainberg, M.A. Differences among HIV-1 subtypes in drug resistance against integrase inhibitors. Infect. Genet. Evol. 2016, 46, 286-291. [CrossRef]

23. Hurt, C.B.; Sebastian, J.; Hicks, C.B.; Eron, J.J. Resistance to HIV integrase strand transfer inhibitors among clinical specimens in the United States, 2009-2012. Clin. Infect. Dis. 2014, 58, 423-431. [CrossRef] [PubMed]

24. Koullias, Y.; Sax, P.E.; Fields, N.F.; Walensky, R.P.; Hyle, E.P. Should We Be Testing for Baseline Integrase Resistance in Patients Newly Diagnosed With Human Immunodeficiency Virus? Clin. Infect. Dis. 2017, 65, 1274-1281. [CrossRef] [PubMed]

25. Zash, R.; Makhema, J.; Shapiro, R.L. Neural-Tube Defects with Dolutegravir Treatment from the Time of Conception. N. Engl. J. Med. 2018, 379, 979-981. [CrossRef] [PubMed]

26. Zash, R.; Holmes, L.; Diseko, M.; Jacobson, D.L.; Brummel, S.; Mayondi, G.; Isaacson, A.; Davey, S.; Mabuta, J.; Mmalane, M.; et al. Neural-Tube Defects and Antiretroviral Treatment Regimens in Botswana. N. Engl. J. Med. 2019, 381, 827-840. [CrossRef]

27. Reefhuis, J.; FitzHarris, L.F.; Gray, K.M.; Nesheim, S.; Tinker, S.C.; Isenburg, J.; Laffoon, B.T.; Lowry, J.; Poschman, K.; Cragan, J.D.; et al. Neural Tube Defects in Pregnancies Among Women With Diagnosed HIV Infection-15 Jurisdictions, 2013-2017. Morb. Mortal. Wkly. Rep. 2020, 69, 1-5. [CrossRef]

28. Garrido, C.; Geretti, A.M.; Zahonero, N.; Booth, C.; Strang, A.; Soriano, V.; De Mendoza, C. Integrase variability and susceptibility to HIV integrase inhibitors: Impact of subtypes, antiretroviral experience and duration of HIV infection. J. Antimicrob. Chemother. 2010, 65, 320-326. [CrossRef]

29. Lataillade, M.; Chiarella, J.; Kozal, M.J. Natural polymorphism of the HIV-1 integrase gene and mutations associated with integrase inhibitor resistance. Antivir. Ther. 2007, 12, 563-570.

30. El Bouzidi, K.; Kemp, S.A.; Datir, R.P.; Murtala-Ibrahim, F.; Aliyu, A.; Kwaghe, V.; Frampton, D.; Roy, S.; Breuer, J.; Sabin, C.A.; et al. High prevalence of integrase mutation L74I in West African HIV-1 subtypes prior to integrase inhibitor treatment. J. Antimicrob. Chemother. 2020, published online ahead of print 27 February 2020. [CrossRef] 
31. Tzou, P.L.; Rhee, S.Y.; Descamps, D.; Clutter, D.S.; Hare, B.; Mor, O.; Grude, M.; Parkin, N.; Jordan, M.R.; Bertagnolio, S.; et al. Integrase strand transfer inhibitor (INSTI)-resistance mutations for the surveillance of transmitted HIV-1 drug resistance. $J$. Antimicrob. Chemother. 2020, 75, 170-182. [CrossRef] [PubMed]

32. Cahn, P.; Pozniak, A.L.; Mingrone, H.; Shuldyakov, A.; Brites, C.; Andrade-Villanueva, J.F.; Richmond, G.; Buendia, C.B.; Fourie, J.; Ramgopal, M.; et al. Dolutegravir versus raltegravir in antiretroviral-experienced, integrase-inhibitor-naive adults with HIV: Week 48 results from the randomised, double-blind, non-inferiority SAILING study. Lancet 2013, 382, 700-708. [CrossRef]

33. Walmsley, S.L.; Antela, A.; Clumeck, N.; Duiculescu, D.; Eberhard, A.; Gutiérrez, F.; Hocqueloux, L.; Maggiolo, F.; Sandkovsky, U.; Granier, C.; et al. Dolutegravir plus abacavir-lamivudine for the treatment of HIV-1 infection. N. Engl. J. Med. 2013, 369, 1807-1818. [CrossRef] [PubMed]

34. Venter, W.D.F.; Moorhouse, M.; Sokhela, S.; Fairlie, L.; Mashabane, N.; Masenya, M.; Serenata, C.; Akpomiemie, G.; Qavi, A.; Chandiwana, N.; et al. Dolutegravir plus Two Different Prodrugs of Tenofovir to Treat HIV. N. Engl. J. Med. 2019, $381,803-815$. [CrossRef] [PubMed]

35. The NAMSAL ANRS 12313 Study Group; Mpoudi-Etame, M.; Omgba Bassega, P.; Eymard-Duvernay, S.; Leroy, S.; Boyer, S.; Peeters, M.; Calmy, A.; Delaporte, E. Dolutegravir-Based or Low-Dose Efavirenz-Based Regimen for the Treatment of HIV-1. N. Engl. J. Med. 2019, 381, 816-826. [CrossRef] [PubMed]

36. Miller, V.; Stürmer, M.; Staszewski, S.; Gröschel, B.; Hertogs, K.; de Béthune, M.P.; Pauwels, R.; Harrigan, P.R.; Bloor, S.; Kemp, S.D.; et al. The M184V mutation in HIV-1 reverse transcriptase (RT) conferring lamivudine resistance does not result in broad cross-resistance to nucleoside analogue RT inhibitors. AIDS 1998, 12, 705-712. [CrossRef] [PubMed]

37. Harrigan, P.R.; Stone, C.; Griffin, P.; Nájera, I.; Bloor, S.; Kemp, S.; Tisdale, M.; Larder, B.; CNA2001 Investigative Group. Resistance profile of the human immunodeficiency virus type 1 reverse transcriptase inhibitor abacavir (1592U89) after monotherapy and combination therapy. J. Infect. Dis. 2000, 181, 912-920. [CrossRef]

38. Brenner, B.G.; Turner, D.; Wainberg, M.A. HIV-1 drug resistance: Can we overcome? Expert Opin. Biol. Ther. 2002, 2, 751-761. [CrossRef]

39. Rhee, S.Y.; Taylor, J.; Wadhera, G.; Ben-Hur, A.; Brutlag, D.L.; Shafer, R.W. Genotypic predictors of human immunodeficiency virus type 1 drug resistance. Proc. Natl. Acad. Sci. USA 2006, 103, 17355-17360. [CrossRef] [PubMed]

40. Whitcomb, J.M.; Parkin, N.T.; Chappey, C.; Hellmann, N.S.; Petropoulos, C.J. Broad nucleoside reverse-transcriptase inhibitor cross-resistance in human immunodeficiency virus type 1 clinical isolates. J. Infect. Dis. 2003, 188, 992-1000. [CrossRef]

41. Kuritzkes, D.R.; Quinn, J.B.; Benoit, S.L.; Shugarts, D.L.; Griffin, A.; Bakhtiari, M.; Poticha, D.; Eron, J.J.; Fallon, M.A.; Rubin, M. Drug resistance and virologic response in NUCA 3001, a randomized trial of lamivudine (3TC) versus zidovudine (ZDV) versus ZDV plus 3TC in previously untreated patients. AIDS 1996, 10, 975-981. [CrossRef] [PubMed]

42. Frost, S.D.; Nijhuis, M.; Schuurman, R.; Boucher, C.A.; Brown, A.J. Evolution of lamivudine resistance in human immunodeficiency virus type 1-infected individuals: The relative roles of drift and selection. J. Virol. 2000, 74, 6262-6268. [CrossRef]

43. Descamps, D.; Flandre, P.; Calvez, V. Mechanism of virologic failure in previously untreated HIV-infect-ed patients from a trial of induction-maintenance therapy. JAMA 2000, 283, 205-211. [CrossRef]

44. Wei, X.; Liang, C.; Gotte, M.; Wainberg, M.A. The M184V mutation in HIV-1 reverse transcriptase reduces the restoration of wild-type replication by attenuated viruses. AIDS 2002, 16, 2391-2398. [CrossRef] [PubMed]

45. National AIDS Secretariat 2016. National HIV/AIDS Monitoring and Evaluation Plan 2016-2020. Available online: https: //www.nas.gov.sl/images/stories/publications/2016\%20-\%202020\%20HIV\%20M\&E-Plan.pdf (accessed on 22 June 2021). 